\title{
Renewable Green hydrogen energy impact on sustainability performance
}

\author{
Asem Alzoubi \\ International Energy Consultant INTEC \& Hamm-Lippstadt University of Applied Sciences, Germany, \\ asem.alzoubi@gopa-intec.de
}

\begin{abstract}
In today's world, the major source of energy is fossil fuels, which are nonrenewable and cannot be used once exhausted. At the start of the twenty-first century, main challenges with current energy infrastructure throughout the world were a finite supply of fossil fuels, everincreasing energy use, and the growing environmental impact of greenhouse gas emissions. Fossil fuel energy is economical due to existing infrastructure, but it has significant downsides and has a severe impact on the environment.

As a result, renewable energy sources are being investigated as potential contenders to supply the bulk of energy demands. Hydrogen is the least harmful to the environment of these fuels. Hydrogen is a clean, long-lasting fuel with the potential that is the source of future global energy. It may potentially be used to replace current fossil-fuel-based energy infrastructure. This is seen as a solution to the above-mentioned challenges, such as global warming and environmental degradation. It is impossible to overestimate the relevance of environmental and economic factors in the development of hydrogen infrastructure. This article discusses the many aspects of hydrogen, including as manufacturing, storage, and applications, with a focus on the environment and the economy.
\end{abstract}

Keywords: Renewable energy, Green hydrogen energy, sustainability performance 


\section{INTRODUCTION:}

While minimizing the effects of global warming, the hydrogen $(\mathrm{H} 2)$ market has the potential to act a substantial part within worldwide power mix. To pass the twofold test, government authorities, corporate leaders, engineers, and buyers must work together to make a cautious and meaningful step. Every year, roughly 70 million tons of $\mathrm{H} 2$ are produced across the world (MTPA). Furthermore, H2 is mostly originated from coal and petroleum gas; the Energy Information Administration (EIA) estimated that the $\mathrm{H} 2$ generation uses $7 \%$ of all flammable gas. (IEA, 2019 a)

They are mostly used in the development of high relative resources such as methanol, alkali, and gas-to-fluids (GTL) power, as well as refinement and steel production. As a result, $\mathrm{H} 2$ serves as a critical middle ground in industry. In any event, pure $\mathrm{H} 2$ consumption accounts for just around $6 \%$ of overall $\mathrm{H} 2$ output, indicating that it plays a little role in the world energy balance. Despite the fact that hydrogen is required for the manufacturing of relatively high quality goods, problem with manufacturing of $\mathrm{H} 2$ is that it is frequently obtained methods that are based on fuel upgrading of methane, coal, and biomass gasification, for example, all yield fossil fuel by products and other ozone-depleting substances. (IEA, 2019 a)

Hydrogen is predicted to make a substantial contribution to transportation, according to the Hydrogen Council, a United Nations group under the World Economic Forum (about 150 MTPA), modernization (approximately 110 MTPA), power production (over 140 MTPA), and other industries. As a result, there is a significant potential to create Hydrogen from environmentally friendly sources for the purpose to fulfils the growing need for Hydrogen in transport sector and other applications. (IEA, 2019 a)

By 2050, The International Maritime Institution (IMO) is a United Nations organization that deals with maritime issues, wants to decrease ozone-depleting chemical emissions in half from present levels. To achieve these goals, they demanded a transition in the delivery region from dependency on petroleum goods to an energy blend that included low carbon discharge powers. Green hydrogen is regarded as a carbon-neutral fuel. (IEA, 2019 b)

Sustainable growth demands a steady supply of fossil fuels at a fair price, with minimum or no negative consequences. In actuality, coal and gas reserves are limited, and so lacked the traits required for long-term growth and survival, whereas renewable energy sources are abundant. (I R. M. Dincer, 2004). Environmentally reach energy, in particular, is the most cost-effective and environmentally benign means to boost long-term technical advancement 
and people's standard of living, along with the industrialization. As a result, long-term and an effective $\mathrm{H} 2$ energy policy must be devised for the purpose toencourage the use of $\mathrm{H} 2$ resources obtained from sources of non-fossil fuels and hydrogen technologies based on renewable energy sources. (Midilli A A. M., 2005)

The purpose of ongoing research is to identify the link between $\mathrm{H} 2$ energy systems and worldwide economic growth and sustainability, as well as on the importance of $\mathrm{H} 2$ based energy sources derived from renewable energy systems in long-term manufacturing. As a result, the study's primary objectives are to enhance our understanding of $\mathrm{H} 2$ based energy sources' long-term viability and to encourage the strategic deployment of hydrogen power systems towards long-term growth. This study also looks at key strategies to renewable power energy system based on the H2, as well as global sustainability initiatives.

\section{LITERATURE REVIEW:}

There is a huge need to construct a Rational and systematic efficient framework to evaluate the influence of Environmentally reach energy-based $\mathrm{H} 2$ power systems on environmental sustainability, world stability, and results reflect. (Dincer I R. M., 2005)

Midilli has recently produced empirical formulations for worldwide economic growth and destabilization, and also environmentally reach energy alternatives for the long-term sustainability and their interdependencies. Dincer and Rosen went on to define long lasting positive enhancements as the intersection of energy, ecological, financial, physical, and social sustainability. This research, in general, add to existing research on hydrogen power systems and their significance in long production. (Dincer I R. M., 2005) As a result, the following sections will now be discussed:

\subsection{Worldwide economic growth and the $\mathrm{H} 2$ based energy sources system:}

The usage of fossil fuels has been connected to global climate change, global energy disputes, and energy resource constraints, constituting an increasing danger to worldwide economic growth. These negative consequences can be seen on a local, regional, and global scale. Significant global problems will almost certainly increase if fossil fuels are used more 
extensively. Global population increase, fast technological advancement, and rising energy consumption all add to this worry.

In the past, fossil fuels, the primary source of energy may have been employed to alleviate global energy issues. However, due to significant growth in global energy demand and consumption, , fossil fuels cannot remain the primary source of energy indefinitely. (Contreras A, 2009)

These reasons create a substantial incentive to the generation of $\mathrm{H} 2$ from sources that does not uses fossil fuel and the implementation of Environmentally reach energy coupled energy system based on the $\mathrm{H} 2$ to adjust for the constraints of conventional resources and enhance worldwide economic growth. If worldwide economic growth is improved through the use of $\mathrm{H} 2$ based energy sources and technology, the hydrogen-based measure of the sustainability is projected to grow. (Conte M, 2001)

For the purpose to reduce the consequences of usage of the fossil fuel resources, increase hydrogen generation from non-fossil fuel resources, and ensure worldwide economic growth and sustainability, $\mathrm{H} 2$ based energy sources plans and a hydrogen-based global sustainability road map should be developed and executed. As a result, actual implementations of these fundamental needs might produce a variety of outcomes, including,

- Decrease the use of fossil fuels;

- Decrease tensions between nations over energy resources;

- Make it easier or more necessary to develop new technologies,

- Minimize pollution of the air, water, and land, as well as forest loss; and

- Reduce energy-related diseases and fatalities. (Conte M, 2001)

\subsection{H2 based energy sources system and sustainability:}

Long lasting positive enhancements necessitates a long-term supply of $\mathrm{H} 2$ based energy sources that is immediately and sustainably accessible at a fair cost, and that may be used for almost all essential tasks regardless of negatively impacting society. One of the key priorities of energy policymakers throughout the world should be to promote energy system based on the H2 for sustainability and worldwide economic growth. (Midilli A A. M., 2004) 
In terms of flexibility, adaptability, and low operating costs, environmentally reach energy-based energy system based on the $\mathrm{H} 2$ differ greatly from customed practise to obtain energy from fossil fuels technology (e.g., large capital investments, long implementation lead times, operating cost uncertainties regarding future fuel costs). Traditional energy systems can be expensive and environmentally unfriendly, but a $\mathrm{H} 2$ based energy sources system based on renewable power can be attained at good cost that is economic and according to the environmental friendly option. Furthermore, $\mathrm{H} 2$ based energy sources and hydro power sources may play an essential part in addressing energy demands in both household and industrial sectors, which is critical for sustainable. (Midilli A A. M., 2004)

Environmentally reach energy-based $\mathrm{H} 2$ based energy sources solutions have lately emerged as a vital component of the stability and sustainability of $\mathrm{H} 2$ based energy sources:

- They have minimal or no certain negative environmental effects. H2 based energy sources resources are available in a variety of forms, allowing for a wide range of uses.

- They are unaffected by depletion. If employed effectively in the relevant applications, energy system based on the $\mathrm{H} 2$ can have a stable and productive way for supply of energy for nearly endless span of time.

- They advocate for system devolution and semi-independent native strategies that seem to be moderately of the national network, increasing system flexibility and providing economic benefits to small, isolated areas.

- Furthermore, equipment's small size minimizes time it takes from conception to operation, giving it more flexibility in taking action to unpredictably changing progress in energy consumption.

The global need for development of energy through sustainable ways is steadily rising. For both emerging and established countries to attain worldwide economic growth and sustainability, widespread deployment of a $\mathrm{H} 2$ based energy sources system based on renewable energy may be critical. As a result, H2 based energy sources and technology are required for worldwide economic growth and valuable economic progress. The relationship between an Environmentally reach energy-based H2 based energy sources system and sustainability is critical for both established and developing (or developing) countries. (Afgan NH, 2004)

In addition, looking at the links between the $\mathrm{H} 2$ based energy sources system and longterm development reveals that green technology is inextricably linked to long-term 
development. As a result, achieving $\mathrm{H} 2$ based energy sources-based long lasting positive enhancement necessitates the use of $\mathrm{H} 2$ based energy sources from sources that does not uses fossil fuel and energy system based on the H2, as well as efficient $\mathrm{H} 2$ based energy sources resource usage. (Afgan NH, 2004)

Taking into mind these critical factors, the benefits of an Environmentally reach energybased $\mathrm{H} 2$ based energy sources system may be described as follows:

- Hydrogen may contribute to environmental sustainability since it is a high-quality, ecologically friendly energy that is also a safe, trustworthy energy transporter that generates no harmful exhaust.

- Hydrogen may initiate environmental balance since it easily can distribute through pipelines.

- As a chemical feedstock in petrochemicals, food, microelectronics, ferrous and nonferrous metals, chemical and polymer synthesis, and metallurgical processes, hydrogen may also be used as an energy carrier in clean and sustainable energy systems.

- Because H2 can be used in so many aspects of business and everyday life, it is easier to move to a hydrogen economy, ensuring economic and social sustainability.

\subsection{Factors and solutions for ensuring the sustainability of $\mathrm{H} 2$ based energy sources:}

Energy system based on the $\mathrm{H} 2$ will play a crucial part in future energy situations. The most essential factor in deciding the specified purpose of $\mathrm{H} 2$ based energy sources and technology will most likely be energy demand. In the future, energy system based on the H2 are predicted to supplant fossil fuel-based energy systems as the primary portable energy carrier for household and industrial uses. Hydrogen production in the world has reached 50 million tons per year (45 billion kg per year), accounting for around $2 \%$ of global energy use. Annual worldwide hydrogen use, on the other hand, is now in the 400-500 billion Nm3 range. Around 97 percent of this total comes from captive or internal production, with only approximately $3 \%$ coming from merchant sources. (James, 2003)

About 99 percent of total is derived by carbon fuels, mostly gas steam reformation. Different methods of synthesis and energy sources are used to make gas. Gas is produced by utilizing alternative fuels such as hydroelectric, photovoltaic, and air to produce crude oil and/or liquid. For example, electrolytic with electricity may create 108.7 kilo of one chemical 
element gas from $1 \mathrm{~m} 3$, and the power of this amount of gas is equivalent to 4221 gallons of gas. Steam is used in the manufacture of gas, which is fuelled by either fossil or renewable energy sources. (James, 2003)

Consider the energy capacity for every volume, usage effectiveness factor $(\mathrm{u}=\mathrm{f} / \mathrm{h}=$ 1), usage stability (which would be high for hydrogen), plan of action, polluted air and physical impacts (which can be lesser for hydrogen, based on energy source used to produce it, especially since $\mathrm{CO} 2$ would not be a necessary waste) of hydrogen fuel. Hydrogen's properties as an energy carrier include being limitless, safely storable and transportable, widely used in a number of applications, created through a variety of techniques and from a diversity of ways, and very affordable to use. As a result, the shift to a hydrogen-based energy market is taking its time but will almost certainly not be completed until the mid or late decade. (James, 2003)

Planning for hydrocarbon fuel sources established and driven by strong primary forces and connected centers should encompass sociological, ecological, energy, financial, industrial, and political components of the hydrogen-based system in order to secure global economic development and sustainability. Certain strategic plans should be made and analysed in order to put $\mathrm{H} 2$ based energy resources strategy into action and illustrate the importance of a renewable power $\mathrm{H} 2$ based energy sources system for sustainability. The research depicts strategic plans, as well as related components, for the use of an Environmentally reach energybased $\mathrm{H} 2$ based energy sources system for greater sustainability in this regard. As a consequence, such necessary initiatives might play a critical role in offering industry and economic help for the transformation to a hydrogen energy and resource system based on the H2 molecule:

Projections for $\mathrm{H} 2$ based energy sources are being monitored and analysed.

- The govt's and the public majority's commitment for the economy is based on H2 sources of energy;

- Manufacturing, usage, delivery, exchange, administration, and marketing of H2-based energy sources;

- H2-based sustainable energy system: research, development, and deployment

- The focuses on the design of environmental systems that rely on H2 based energy sources, as well as the availability, productivity, and reliability of $\mathrm{H} 2$ based energy sources and technologies. 


\section{PROBLEM STATEMENT:}

Fossil fuels, which are nonrenewable and cannot be utilized once depleted, are the primary source of energy in today's globe. The primary issues with present energy infrastructure throughout the world at the turn of the twenty-first century were a finite supply of fossil fuels, ever-increasing energy usage, and the growing environmental effect of greenhouse gas emissions. Because of existing infrastructure, fossil fuel energy is cost effective, but it has considerable drawbacks and has a negative influence on the environment.

Carbon and other greenhouse gases are emitted into the atmosphere when fossil fuels are burnt. Significant changes in Earth's climate have resulted from excessive greenhouse gas accumulation in the atmosphere, a trend that is only anticipated to intensify as more fossil fuels are used. As a result, they are not only the most expensive resources, but also the most environmentally damaging. (Conte M, 2001)

\section{METHODOLOGY:}

To complete this review, three alternative methodologies were used: (1) Computerized searches of selected databases including such PubMed, ERIC, Medline, and PDF documents; (2) Reference section in APA Format of current evaluations and original research; and (3) The references and assessed data were further supported by statistical analysis utilizing a program like statista.com.

Following the fundamental methodologies, a systematic study of 15 important databases on Green $\mathrm{H} 2$ based energy sources was conducted for the article, and its function in sustainable performance was investigated. Some items were removed from the database after a review because they did not meet the inclusive criteria.

Original research papers and articles relevant to green hydrogen and its impact were included in the inclusive criteria that are: (1) Separate data on Green Hydrogen resources that was relevant in a sustainable performance perspective; (2) English Language; (3) Visible reviewed articles that clearly specify the desired data; (4) Analyzed reports on the basis of sustainable performance as a dependent variable; (5) Researched the correlations or relationships between Green Hydrogen resources and long-term performance, using data collected from demographics, behavioral characteristics, and environmental factors. The papers were gathered from research conducted between 2004 and 2021. 


\section{DISCUSSION AND ANALYSIS:}

Solar, wind, hydro, and nuclear energy may all contribute to Environmentally reach energy-based hydrogen generation, which can help to enhance worldwide economic growth and sustainability. The worldwide economic growth and sustainability ratios based on $\mathrm{H} 2$ based energy sources are increasing as the $\mathrm{H} 2$ based energy sources utilization ratio rises. The greatest H2 based energy sources impact ratios between 73.333 percent and 100 percent offer the best outcomes for $\mathrm{H} 2$ based energy sources-based sustainability ratios. Using 10\%, 20\%, and 50\% non-fossil fuel hydrogen utilization ratios in 2010, we get $\mathrm{H} 2$ based energy sources-based sustainability ratios of 0.213 percent, 1.086 percent, and 11.111 percent for a 73.333 percent H2 based energy sources impact ratio, and 0.291 percent, 1.481 percent, and 15.161 percent for a $100 \% \mathrm{H} 2$ based energy sources impact ratio, respectively.

In Example 1, the optimum effect ratio of $\mathrm{H} 2$ based energy sources is between 73.334 $\%$ and 100 percent. As a result, in fact, the greatest proportion (e.g., 100\%) of the simulated results show in case- 1 should be employed to achieve the highest hydrogen-based sustainable ratio, which appears to give superior results. Research must be applied in practice to increase the $\mathrm{H} 2$ based energy sources-based measure of process involves on $\mathrm{H} 2$ based power sources methods, factors, and programs for a larger $\mathrm{H} 2$ based power sources impact ratio.

Hydrogen-based policies, regulations, and initiatives are undoubtedly essential to ensure global economic development and sustainability while mitigating the negative consequences of fossil-fuel use. As a result, it is recommended that, while considering $\mathrm{H} 2$ based energy sources plans, the importance of an Environmentally reachable energy-based $\mathrm{H} 2$ based energy sources system that reduces global difficulties and provides a sustainable energy system be stressed.

Strategies, variables, and programs based on $\mathrm{H} 2$ seem to be critical for long-term positive improvement and better durability in a developed state. For the goal of establishing and implementing an eco friendly energy-based energy system that is based on $\mathrm{H} 2$ and uses. As a consequence of global environmental challenges, energy supplies and availability concerns, and technological advancements, they are definitely have become more important to individuals.

If the current rate of rise in fossil fuel usage continues, the planet will be subjected to a slew of negative consequences. More fossil fuel usage will destabilize the planet and exacerbate local and global environmental issues, leading to greater global instability. As a 
result, it is suggested that fossil fuel use be decreased and that a $\mathrm{H} 2$ based energy sources system based on Environmentally reach energy be progressively built.

\section{CONCLUSION:}

Hydrogen has been utilized as a feedstock in a number of important businesses for decades. Hydrogen might provide the "missing link" in delivering large amounts of renewable energy to sectors like transportation, industry, and existing natural gas consumption that would otherwise difficult to decarbonize through direct electrification. The hydrogen fuel cell can assist accelerate the energy transition by committing to a protracted aim of raising significant investment in low-carbon hydrogen research and commercialization while permitting interaction with other industries (e.g., industry, electricity system, buildings, transport, and global trading). Hydrogen has the capability of transporting renewable energy across long distances.

Hydrogen might be created in places with abundant and low-cost renewable energy sources, and then transported to areas with limited capacity or higher renewable energy production costs. Hydrogen-based renewable energy transportation may be constructed in a range of sizes, from tiny to huge. As hydrogen becomes more extensively utilized, it will necessitate cross-sector collaboration in hydrogen generation, storage, transportation, and distribution. Hydrogen possesses the technology to facilitate a long-term energy transition, but it must be developed quickly for the purpose to achieve cost reductions and economic feasibility.

Large-scale applications that can rapidly provide large-scale economics, require little infrastructure, and are the highest performing solution in their respective domains should be the key emphasis. In this regard, heavy-duty transportation (large fleets of hydrogen buses, trucks, trains on non-electrified lines, and maritime, among other things) and large industry (refineries, chemicals plants, methanol production, and maritime, among other things) will be ideal starting points, where renewable hydrogen is a good solution for achieving climatic goals.

In comparison to the fossil fuel industries, it is clear that significant infrastructure investment will be made to supply clean hydrogen to end users. The cost of renewable energy has lately plummeted considerably, making it feasible. 
Considering the $\mathrm{H} 2$ based energy sources strategies presented in this paper, it is reasonable to conclude that providing the necessary incentives and interactions among countries, scientists, researchers, societies, and others is the most important scenario for encouraging the transition to hydrogen economy and technologies and promoting an environmentally friendly $\mathrm{H} 2$ based energy sources system.

As a result, it is anticipated that this paper will contribute to:

- Assist in comprehending key concepts and concerns related to global economy stability through hydrogen-based energy sources and sustainability of the global market.

- Establish a relationship between use of H2 based energy sources and the development of a sustainable future.

- Promote the long-term systematic use of H2 (hydrogen-based energy) as a source of energy.

- For the purpose to improve energy supply, increase incentive for the use of $\mathrm{H} 2$ based energy sources techniques.

- Consider the $\mathrm{H} 2$ based energy system as a means of reducing negative environmental consequences.

- To explore various H2 based energy sources solutions for sectoral application, create a scientific platform. 


\section{REFERENCES}

[1]. Afgan NH, C. M. (2004). Sustainability assessment of energy system based on the H2. Int J H2 based energy sources, 29:1327-42.

[2]. Conte M, I. A. (2001). Hydrogen economy for a long lasting positive enchancement: state-of-the-art and technological perspectives. Int J Power Sources , 100:171-87.

[3]. Contreras A, C. J. (2009). Solar-hydrogen: an energy system for long lasting positive enchancement in Spain. . Int J H2 based energy sources , 24:1041-52.

[4]. Council, H. (2017). Hydrogen Scaling Up - A Sustainable Pathway for the Global Energy Transition. Hydrogen Council (2017)., 34-39. Retrieved December 15, 2021 from https://hydrogencouncil.com/wp-content/uploads/2017/11/Hydrogen-scaling-upHydrogen-Council.pdf

[5]. Dincer I, R. M. (2004). Exergy as a driver for Achieving Sustainability. . Int J Environmentally reach energy, (1):1-19.

[6]. Dincer I, R. M. (2005). Thermodynamic aspects of renewables and long lasting positive enchancement. . Renewable Sustainable Energy Rev , 9: 169-89.

[7]. IEA. (2019 a). The Future of Hydrogen - Seizing Today's Opportunities Available online at: (accessed September 30, 2020). Technology Report, 32-34. Retrieved December 15, 2021 from https://www.iea.org/reports/the-future-of-hydrogen

[8]. IEA. (2019 b, December 12). World Energy Outlook 2019. From Google Scholars: https://www.iea.org/reports/world-energy-outlook-2019

[9]. James, B. (2003). On hydrogen futures: toward a sustainable energy system. Int J H2 based energy sources, 28:131-3.

[10]. Midilli A, A. M. ( 2004). On H2 based energy sources strategy: the key role in this century and beyond. . Proceedings of the first Cappadocia international mechanical engineering symposium, 32-40.

[11]. Midilli A, A. M. (2005). On hydrogen and H2 based energy sources strategies-I: current status and needs. Renewable Sustainable Energy Rev , (3):255-71. 
[12]. Aziz, N., \& Aftab, S. (2021). Data Mining Framework for Nutrition Ranking: Methodology: SPSS Modeller. International Journal of Technology, Innovation and Management (IJTIM), 1(1), 85-95.

[13]. Radwan, N., \& Farouk, M. (2021). The Growth of Internet of Things (IoT) In The Management of Healthcare Issues and Healthcare Policy Development. International Journal of Technology, Innovation and Management (IJTIM), 1(1), 69-84.

[14]. Cruz, A. (2021). Convergence between Blockchain and the Internet of Things. International Journal of Technology, Innovation and Management (IJTIM), 1(1), 34-53.

[15]. Lee, C., \& Ahmed, G. (2021). Improving IoT Privacy, Data Protection and Security Concerns. International Journal of Technology, Innovation and Management (IJTIM), $1(1), 18-33$.

[16]. Alzoubi, A. (2021) The impact of Process Quality and Quality Control on Organizational Competitiveness at 5-star hotels in Dubai. International Journal of Technology, Innovation and Management (IJTIM). 1(1), 54-68

[17]. Al Ali, A. (2021). The Impact of Information Sharing and Quality Assurance on Customer Service at UAE Banking Sector. International Journal of Technology, Innovation and Management (IJTIM), 1(1), 01-17.

[18]. Kashif, A. A., Bakhtawar, B., Akhtar, A., Akhtar, S., Aziz, N., \& Javeid, M. S. (2021). Treatment Response Prediction in Hepatitis C Patients using Machine Learning Techniques. International Journal of Technology, Innovation and Management (IJTIM), 1(2), 79-89.

[19]. Akhtar, A., Akhtar, S., Bakhtawar, B., Kashif, A. A., Aziz, N., \& Javeid, M. S. (2021). COVID-19 Detection from CBC using Machine Learning Techniques. International Journal of Technology, Innovation and Management (IJTIM), 1(2), 65-78.

[20]. Eli, T. (2021). Students Perspectives on the Use of Innovative and Interactive Teaching Methods at the University of Nouakchott Al Aasriya, Mauritania: English Department as a Case Study. International Journal of Technology, Innovation and Management (IJTIM), 1(2), 90-104.

[21]. Alsharari, N. (2021). Integrating Blockchain Technology with Internet of things to Efficiency. International Journal of Technology, Innovation and Management (IJTIM), 1(2), 01-13. 
[22]. Mehmood, T. (2021). Does Information Technology Competencies and Fleet Management Practices lead to Effective Service Delivery? Empirical Evidence from ECommerce Industry. International Journal of Technology, Innovation and Management (IJTIM), 1(2), 14-41.

[23]. Miller, D. (2021). The Best Practice of Teach Computer Science Students to Use Paper Prototyping. International Journal of Technology, Innovation and Management (IJTIM), 1(2), 42-63.

[24]. S. Y. Siddiqui, A. Haider, T. M. Ghazal, M. A. Khan, I. Naseer, S. Abbas, M. Rahman, J. A. Khan, M. Ahmad, M. K. Hasan, A. M. A, and K. Ateeq, "IOMT cloudbased intelligent prediction of breast cancer stages empowered with Deep Learning," IEEE Access, vol. 9, pp. 146478-146491, Oct. 2021.

[25]. S. Abbas, Y. Alhwaiti, A. Fatima, M. A. Khan, M. Adnan Khan, T. M. Ghazal, A. Kanwal, M. Ahmad, and N. Sabri Elmitwally, "Convolutional neural network based intelligent handwritten document recognition," Computers, Materials \& Continua, vol. 70, no. 3, pp. 4563-4581, Oct. 2021.

[26]. T. M. Ghazal, S. Abbas, S. Munir, M. A. Khan, M. Ahmad, G. F. Issa, S. Binish Zahra, M. Adnan Khan, and M. Kamrul Hasan, "Alzheimer disease detection empowered with transfer learning," Computers, Materials \& Continua, vol. 70, no. 3, pp. 5005-5019, Oct. 2021.

[27]. N. Ali, T. M. Ghazal, A. Ahmed, S. Abbas, M. A. Khan, H. M. Alzoubi, U. Farooq, M. Ahmad, and M. Adnan Khan, "Fusion-based supply chain collaboration using Machine Learning Techniques,” Intelligent Automation \& Soft Computing, vol. 31, no. 3, pp. 1671-1687, Oct. 2021.

[28]. M. K. Hasan, T. M. Ghazal, A. Alkhalifah, K. A. Abu Bakar, A. Omidvar, N. S. Nafi, and J. I. Agbinya, "Fischer linear discrimination and quadratic discrimination analysisbased data mining technique for internet of things framework for Healthcare," Frontiers in Public Health, vol. 9, Oct. 2021.

[29]. R. Bibi, Y. Saeed, A. Zeb, T. M. Ghazal, T. Rahman, R. A. Said, S. Abbas, M. Ahmad, and M. A. Khan, "Edge AI-based automated detection and classification of road anomalies in VANET using Deep Learning," Computational Intelligence and Neuroscience, vol. 2021, pp. 1-19, Sep. 2021.

[30]. M. Adnan Khan, T. M. Ghazal, S.-W. Lee, and A. Rehman, "Data Fusion-based machine learning architecture for intrusion detection," Computers, Materials \& Continua, vol. 70, no. 2, pp. 3399-3413, Sep. 2021. 
[31]. T. M. Ghazal, S. Noreen, R. A. Said, M. Adnan Khan, S. Yamin Siddiqui, S. Abbas, S. Aftab, and M. Ahmad, "Energy demand forecasting using fused machine learning approaches," Intelligent Automation \& Soft Computing, vol. 31, no. 1, pp. 539-553, Sep. 2021.

[32]. T. M. Ghazal, "Internet of things with Artificial Intelligence for Health Care Security,” Arabian Journal for Science and Engineering, Aug. 2021.

[33]. T. M. Ghazal, M. K. Hasan, M. T. Alshurideh, H. M. Alzoubi, M. Ahmad, S. S. Akbar, B. Al Kurdi, and I. A. Akour, "IOT for Smart Cities: Machine Learning Approaches in smart healthcare-A Review," Future Internet, vol. 13, no. 8, p. 218, Aug. 2021.

[34]. Mehmood, T., Alzoubi, H, Alshurideh, M., Al-Gasaymeh, A., \&Ahmed, G. (2019). Schumpeterian Entrepreneurship Theory: Evolution and Relevance. Academy of Entrepreneurship Journal, 25(4). 1-10, doi.org/10.1080/13662716.2016.1216397

[35]. Alzoubi, H., Ahmed, G., Al-Gasaymeh, A., \& Alkurdi, B. (2019). Empirical study on Sustainable Supply Chain Strategies and its impact on Competitive Priorities: The mediating role of Supply Chain Collaboration. Management Science Letters, 10(3), 703708, doi.org/10.5267/j.ms1.2019.9.008

[36]. Alzoubi, H. \& Ahmed, G. (2019). Do Total Quality Management (TQM) Practices Improve Organisational Success? A case study of electronics industry in the UAE. International Journal of Economics and Business Research, 17(4), 459-472, doi.org/10.1504/IJEBR.2019.099975

[37]. Al-Gasaymeh, A., Ahmed, G., Mehmood, T. \& Alzoubi, H. (2019). Co-Integration Tests and the Long-Run Purchasing Power Parity: A Case Study of India and Pakistan Currencies. Theoretical Economics Letters, 9(4), 570-583.

[38]. Alzoubi, H., Abdo M., Al-Gasaymeh, A. \& Alzoubi, A. (2019). An empirical study of e-Service quality and its impact on achieving a value added. Journal of Business and Retail Management Research (JBRMR), 13(4), 138-145.

[39]. Alzoubi, H. (2018). The Role of Intelligent Information System in e-Supply Chain Management Performance. International Journal of Multidisciplinary Thought, 7(2), 363-370.

[40]. Alzoubi, A., Al-Gasaymeh, A., \& Alzoubi, H. (2018). The Impact of Changes in the Qualitative Characteristics of Accounting Information on the Quality of Investment Decisions: A Field Study in the Brokerage Offices. The Journal of Economic and Management Perspectives (JEMP), 12(4), 67-82. 
[41]. Alnazer, N., Alnuaimi, M. \& Alzoubi, H. (2017). Analyzing the Appropriate Cognitive Styles and its effect on Strategic Innovation in Jordanian Universities. International journal of business excellence, 13(1), 127-140, doi.org/10.1504/IJBEX.2017.085799

[42]. Khafajy, N., Alzoubi, H. \& Aljanabee, A. (2016). Analyzing the effect of knowledge management processes in the services' quality in Iraqi commercial banks. International Review of Management and Business Research, 5(1), 302-314.

[43]. Alzoubi, H., Alnazer, N. \& Alzoubi, A. (2016). Exploring the Impact of the use of Business Information systems BIS on the organizational performance effectiveness. International Journal of Business and Management Invention, 5(4), 48-55.

[44]. Alnuaimi, M., Alzoubi, H., Alzubi, A. \& AL-Shinewi, M. (2015). The Impact of Managers Efficiency on Quality of Strategic Decision-making under Crisis Management. European Journal of Business and Management, 7(26), 156-166.

[45]. Alrubaiee, L., Alzubi, H., Hanandeh, R. \& Ali, R. (2015). Investigating the Relationship between Knowledge Management Processes and Organizational Performance: The Mediating Effect of Organizational Innovation. International Review of Management and Business Research, 4(4), 977-997

[46]. Alzoubi, H. \& Khafajy, N. (2015). The Impact of Business Process Management on Business Performance Superiority. International Journal of Business and Management Review, 3(2), 17-34

[47]. Alzubi, H., Mohammad, S. \& Abu-salma, A. (2015). Evaluating Strategic Quality Management Dimensions Using Analytic Hierarchy Process (AHP) and its Impact on Organizational Success. International Journal of Research in Management, 5(1), 137150.

[48]. Mohammad, S., Abu-salma, A. \& Alzoubi, H. (2015). American Muslims'

Perceptions Toward Transforming Islamic Banking System. International Journal of Economics, Commerce and Management, 5(1), 1-16.

[49]. Alrubaiee, L., Al zuobi, H. \& Abu-Alwafa, R. (2013). Exploring the Relationship between Quality Orientation, New Services Development and Organizational Performance. American Academic \& Scholarly Research Journal, 5(3), 315-329.

[50]. Alzoubi, H. \& Khafajy, N. (2010). Analyze the Impact of Managers Awareness of Environmental Uncertainty on Exploiting Strategic Competencies. Egyptian Journal for Commercial Studies, 34(2), 611-625. 
[51]. Al-zu'bi, H. (2010). Applying Electronic Supply Chain Management Using MultiAgent System: A Managerial Perspective. International Arab Journal of e-Technology, 1(3), 106-113.

[52]. Alnuaimi, M., Alzoubi, A. \& Alzoubi, H. (2010). Propose a model for Performance Criteria and measuring its impact for Achieving Excellence. Association of Arab Universities Journal, 56(4), 920-941. 